\title{
Forever Young: How to Control the Elongation, Differentiation, and Proliferation of Cells Using Nanotechnology
}

\author{
R. G. Ellis-Behnke, ${ }^{*}+$ đI Y. X. Liang,* J. Guo,* D. K. C. Tay,* \\ G. E. Schneider, $\mathbb{T}$ L. A. Teather, $\mathbb{W}$ W. Wu, $* \dagger \neq \S$ and K. F. So*t* \\ *Department of Anatomy, The University of Hong Kong Li Ka Shing Faculty of Medicine, Pokfulam, Hong Kong SAR, China \\ $†$ State Key Lab for Brain \& Cognitive Sciences, The University of Hong Kong Li Ka Shing Faculty of Medicine, \\ Pokfulam, Hong Kong SAR, China \\ $¥$ Research Centre of Heart, Brain, Hormone and Healthy Aging, The University of Hong Kong Li Ka Shing Faculty of Medicine, \\ Pokfulam, Hong Kong SAR, China \\ §Research Center of Reproduction, Development and Growth, The University of Hong Kong Li Ka Shing Faculty of Medicine, \\ Pokfulam, Hong Kong SAR, China \\ IIDepartment of Brain and Cognitive Sciences, Massachusetts Institute of Technology, Cambridge, MA, USA
}

\begin{abstract}
Within the emerging field of stem cells there is a need for an environment that can regulate cell activity, to slow down differentiation or proliferation, in vitro or in vivo while remaining invisible to the immune system. By creating a nanoenvironment surrounding PC12 cells, Schwann cells, and neural precursor cells (NPCs), we were able to control the proliferation, elongation, differentiation, and maturation in vitro. We extended the method, using self-assembling nanofiber scaffold (SAPNS), to living animals with implants in the brain and spinal cord. Here we show that when cells are placed in a defined system we can delay their proliferation, differentiation, and maturation depending on the density of the cell population, density of the matrix, and the local environment. A combination of SAPNS and young cells can be implanted into the central nervous system (CNS), eliminating the need for immunosuppressants.
\end{abstract}

Key words: Nanotechnology; Stem cells; PC12; Schwann cells; Neural precursors; Brain; Spinal cord; Regeneration; Tissue engineering; Growth control; Self-assembling nanofiber scaffold (SAPNS)

\section{INTRODUCTION}

With the advent of nanotechnology we are entering a new era of tissue and organ reconstruction. Fine control of the nanodomain will allow for increased targeting of cell placement and therapeutic delivery, amplified by cell encapsulation and implantation. Small changes in the cellular environment can lead to the activation of the apoptotic pathway or even necrosis of the cells weeks after implantation.

The successful storage and implantation of stem cells poses significant challenges for tissue engineering in the nervous system. This is in addition to the challenges inherent to neural regeneration: formation of the glial scar that surrounds the lesions caused by traumatic brain injury (TBI) or stroke, and the cystic cavities in spinal cord injury (SCI) (12).
Scaffolds play a central role in organ regeneration (10). They act as a template and guide for cell proliferation, cell differentiation, and tissue growth, as well as a way to control the release of drugs at rates matching the physiological need of the tissue (31). The surface of the scaffold provides a substrate for cell adhesion and migration, which can influence the survival of transplanted cells or the invasion of cells from the surrounding tissue.

Although many promising strategies have been developed for controlling the release of drugs from scaffolds, there are still challenges to be addressed for these scaffolds to serve as successful treatments $(23,45,56,59,60)$ : (a) precise placement of the cells into the scaffold to prevent migration from the scaffold before it has been repopulated; (b) ability of the scaffold to allow cells to migrate into it, in order to reconstitute the tissue from the surrounding area; and (c) prevention of the acidic

Address correspondence to Rutledge Ellis-Behnke, Department of Anatomy, The University of Hong Kong Li Ka Shing Faculty of Medicine, 1/F, Laboratory Block, 21 Sassoon Road, Pokfulam, Hong Kong SAR, China. Tel: (852) 2819-9205; Fax: (852) 2817-0857; E-mail: rutledge@hkucc. hku.hk or Kwok-Fai So, Department of Anatomy, The University of Hong Kong Li Ka Shing Faculty of Medicine, 1/F, Laboratory Block, 21 Sassoon Road, Pokfulam, Hong Kong SAR, China. Tel: (852) 2819-9220; Fax: (852) 2817-0857; E-mail: hrmaskf@hkucc.hku.hk 
breakdown of the cell scaffold, which results in an adverse environment for cell growth.

Many types of scaffolds, utilizing a wide range of materials, have been used for the regeneration and repair of the nervous system $(47,58)$. In treating TBI or SCI drug-delivering scaffolds may need to be combined with cell transplantation to obtain functional recovery (56).

\section{TYPES OF SCAFFOLDS}

\section{Natural Materials}

Natural materials can impart intrinsic signals within the structure that can enhance tissue formation (46). They include alginate $(26,27,41)$, chitosan $(6,13,14)$, collagen $(1,34)$, fibrin $(21,42-44,48-50)$, and hyaluron $(18,19,24,52)$.

Benefits. Natural materials possess many properties that make them attractive for tissue applications. Many of these materials contain sites for cell adhesion, allowing for cell attachment. These materials also exhibit similar properties to the tissues they are replacing (55).

Drawbacks. Because these materials are obtained from natural sources, they must be purified to ensure that no foreign body response occurs after implantation. Homogeneity of product between lots can be an issue with natural materials (55). In addition, (a) chitosan can cause an allergic reaction (20); (b) fibrin, from blood products, and collagen, from animal products, have been known to cause an immune response (55); (c) some, but not all, natural materials allow for cell infiltration (55); (d) the modulus of these materials may be very different from that of the tissue they are implanted in (8). In a pulsatile environment the materials will shear away from the surrounding tissue, causing additional damage (8); and (e) by creating an environment that will not move in the same way as the surrounding tissues, the cells are subjected to an environment different from their native one; this can lead to a very different expression pattern of genes, one that produces an extracellular environment that is not conducive to repair, possibly leading to the development of tissue unable to function like the original tissue (32).

Recently, a flexible scaffold system has been developed, utilizing both collagen and a synthetic component that can degrade by both hydrolysis and collagenase degradation pathways, as well as support cell growth. This type of scaffold could possibly be used in soft tissue applications (15).

\section{Synthetic Materials}

Synthetic materials have known compositions and can be custom designed with specific properties (46). They include poly(ethylene glycol) (PEG) $(4,29,33,40)$; poly(lactic acid) (PLA)/poly(glycolic acid) (PGA)/poly- (lactic-co-glycolic) acid (PLGA) (2,28,30,38,51); and poly(2-hydroxyethyl methacrylate-co-methyl methacrylate) (pHEMA-MMA) $(3,5,37,53,54)$. PLAs, PLGAs, and MMAs have recently been used to form scaffolds preimpregnated with cells (36); the entire scaffold is then implanted in the damaged tissue area (16).

Benefits. Synthetic materials have many advantages for use as scaffolds. These polymers can be tailored to produce a wide range of mechanical properties and degradation rates. They also have known compositions and can be designed to minimize the immune response. Finally, synthetic polymers can be reacted together to combine the properties that are unique to each (55).

Drawbacks. Degradation by-products can be absorbed by the body and may cause $\mathrm{pH}$ changes around the implantation site, leading to necrosis and delayed apoptosis (55).

\section{Synthetic Biological Materials}

The next generation of cell scaffolds to emerge are designed self-assembling peptides that spontaneously form nanofibers $(23,58-61)$, creating a scaffold-like tissue-bridging structure that provides a framework for axonal regeneration (9). They are formed through the assembly of ionic self-complementary peptides $(22,58-$ 61) and are designed by using alternating positive and negative L-amino acids that form highly hydrated scaffolds in the presence of physiological concentration salts (i.e., saline, tissue culture media, physiological solutions, or human body fluids such as cerebrospinal fluid) $(22,59,60)$. Because these scaffolds assemble using weak ionic bonds and van der Waal's forces the scaffolds are motile and able to disassemble and reassemble in the nanodomain, depending on the charge change.

Benefits. Synthetic biological material allows for high cell implantation densities and enables cells to migrate freely in and out of the scaffold and the surrounding tissue. The material can also be designed to match the modulus of the surrounding tissue (8). There appears to be no immune response when the material is either (a) prebuffered or (b) allows buffering by the surrounding tissue and liquid in the injury site (17). During breakdown there is no decrease of $\mathrm{pH}$ in the local environment.

Drawbacks. Making pure nanomaterials in large quantities can be difficult because the process involves putting molecules together one at a time. To do that with high fidelity, in bulk, is a technological challenge (unpublished observations).

\section{Challenges in Developing Cellular Therapies}

To successfully reconstruct tissues and organs, cellular therapies must integrate into the injury site. For CNS injuries regeneration is not just replacement but re- 
growth of the lost neuronal circuitry, followed by promotion of plasticity of the spared and regenerated neurons $(9,56)$.

PC12 cells will change branching patterns and process densities depending on the modulus of the scaffold. If the modulus is less than 10 pascals $(\mathrm{Pa})$ branching decreases along with neurite density, whereas when the modulus is between 100 and $1000 \mathrm{~Pa}$ branching is more pronounced and the cells exhibit process outgrowth that is longer, with more cells expressing neurite markers $(32,39)$.

Other issues associated with human embryonic stem cell lines include the use of culture systems that rely on serum or feeder cell layers. There is a need for the development of culture methods for human stem cells that involve chemically defined media (56). The end goal for cellular therapies would be to create cell lines for transplantation that do not require immune suppression of the patient (56).

\section{Self-Assembling Nanofiber Scaffold (SAPNS)}

We previously demonstrated that a self-assembling peptide nanofiber scaffold (SAPNS) (10), a solution containing a series of amino acids that flows into an area and self-assembles into a scaffold upon contact with any ionic solution, eliminated the formation of a scar, thus allowing the permissive environment (7) necessary for regeneration and functional return of behavior in the brain. We performed additional work where cells were first implanted in the material, then implanted into the spinal cord (17). The local environment is usually irregular and it is important for a self-assembled cellular scaffold to be able to conform to that environment. In an effective scaffold cells can be added after the material has flowed into the local area, or it can first be premixed into the solution and then the entire material injected into the area where it will conform to the irregular environment.

Here we show the importance of placing cells into a defined system within a three-dimensional (3D) environment, allowing better control over growth and differentiation in order to effectively mimic the extracellular matrix both in vitro and in vivo.

This article will discuss: (a) the appropriate concentration of material based on the type of cells being implanted; (b) determining if the material needs to be prebuffered, or if the cells need to be precultured in the material before it is then injected into the lesion area; (c) controlling the physical environment to make it more permissive for cell migration while at the same time slowing, or even arresting, the proliferation, elongation, and differentiation of the implanted cells; and (d) modulation of the immune system with a unique physical environment around the implant site.

\section{MATERIALS AND METHODS}

\section{Preparation of the SAPNS Solution}

The SAPNS solution was prepared by using RADA16-I dry powder (made in the Ellis-Behnke lab, MIT peptide lab, or purchased from $\mathrm{BD}$ ) and mixed in an Eppendorf tube. The solution contained 5, 10, 20, or $30 \mathrm{mg}$ of RADA16-I powder in $1 \mathrm{ml}$ of Milli-Q water (Millipore), mixed, then sonicated for $30 \mathrm{~s}$ and filtered; this produced $0.5 \%, 1 \%, 2 \%$, or $3 \%$ SAPNS. We took extra care to ensure that the material was pure by mixing the powder into the liquid and letting it sit at room temperature for 1 month. An indication of its purity was that it remained clear and odorless.

\section{PC12 Cell Culture}

PC12 cells were purchased and plated in $10-\mathrm{cm}$ polystyrene dishes, grown in a mixture of Hams F12k medium with $10 \%$ horse serum and $2.5 \%$ fetal bovine serum (FBS). Penicillin and streptomyosin were added along with $2 \mathrm{mM}$ of L-glutamine and $1.5 \mathrm{~g} / \mathrm{L}$ of sodium bicarbonate (32). Cells were used after passage six. Cells were removed with trypsin-EDTA for transfer to the SAPNS. The SAPNS was prebuffered using the culture medium DMEM. The SAPNS at various concentrations was placed in separate wells and DMEM was added and changed in 1-, 10-, and 30-min intervals. The phenol red in the culture medium was used as an indicator for a balanced $\mathrm{pH}$ condition. The cells were transferred to $0.5 \%, 1 \%$, or $2 \%$ SAPNS and implanted into the material. On day 10 nerve growth factor (NGF) was added to assess the viability of the cell after the proliferation delay. Cells were incubated at $37^{\circ} \mathrm{C}$ in $5 \% \quad \mathrm{CO}_{2}$. Medium was changed every 3 days.

\section{Schwann Cells (SC)}

The SCs were isolated as described elsewhere (35, 57). Briefly, the sciatic nerves from adult green fluorescent protein (GFP) transgenic Sprague-Dawley rats ["green rat CZ-004" SD TgN (act-EGFP) OsbCZ-004] were disassociated and placed in culture dishes with DMEM/F12 (Gibco) supplemented with 10\% FBS (Gibco). When the outgrowth of migratory cells (predominantly fibroblasts) reached a near-confluent monolayer around the explants (about 7 days), the explants were transferred to new culture dishes with fresh medium. After three to five such passages (3-5 weeks) the cells that emerged from the explants were primarily SCs. The explants were then transferred to a $35-\mathrm{mm}$ dish containing $1.25 \mu \mathrm{g} / \mathrm{ml}$ dispase, $0.05 \%$ collagenase, and $15 \%$ FBS in DMEM/F12 for incubation overnight at $37^{\circ} \mathrm{C}$ in $5 \% \mathrm{CO}_{2}$. On the following day the explants were dissociated and the cells were plated onto poly-L-lysine (0.01\%; Sigma, St. Louis, MO)-coated dishes in DMEM/F12 with $10 \%$ 
FBS. Later the cultures were refed with the same medium supplemented with $20 \mu \mathrm{g} / \mathrm{ml}$ pituitary extract (Sigma) and $2 \mu \mathrm{M}$ forskolin (Sigma) for dividing. When the SCs reached confluence they were rinsed in $\mathrm{Ca}^{2+}$ and $\mathrm{Mg}^{2+}$-free Hanks balanced salt solute ion (CMFHBSS; Gibco) and briefly treated with $0.05 \%$ trypsin (Gibco) and 0.02\% EDTA (Gibco) in CMF-HBSS. Cells were washed twice in DMEM/F12 with $10 \%$ FBS and transferred into new dishes at a density of $2 \times 10^{6}$ cells per $100-\mathrm{mm}$ dish. When the cells reached confluence again they were collected for transplantation.

\section{Neural Precursor Cells (NPC)}

The generation and characterization of embryonic NPC cultures have been previously described $(11,25)$. The hippocampi of embryonic day 16 (E16) embryos of GFP-transgenic Sprague-Dawley rats were dissected in cooled CMF-HBSS and dissociated mechanically. The cells were collected by centrifugation and resuspended in DMEM/F12 supplemented with B27 supplement (2\%, Gibco), N2 (1\%, Gibco), epidermal growth factor (EGF, $20 \mathrm{ng} / \mathrm{ml}$, Gibco), basic fibroblast growth factor (bFGF, $20 \mathrm{ng} / \mathrm{ml}$, Sigma), penicillin (100 U/ml), and streptomycin $(100 \mu \mathrm{g} / \mathrm{ml})$. The cells were adjusted to $1 \times 10^{5}$ cells $/$ $\mathrm{ml}$ and introduced into culture flasks. Half of the medium was replaced every 3 days. Typically the cells were mechanically dissociated approximately once each week and reseeded at approximately $1 \times 10^{5}$ cells $/ \mathrm{ml}$ and then implanted into SAPNS of $1 \%, 2 \%$, and $3 \%$ concentrations. Pictures were then taken at 5, 7, 9, 12, 15, and 34 days. This was repeated in a non-GFP-expressing cell line and pictures were taken at 3, 5, 7, and 9 days.

\section{Schwann Cells in 3D Culture Within the SAPNS}

Before transplantation the SCs, obtained from the sciatic nerves of GFP rats, were cultured within $1 \%$ SAPNS scaffold. Briefly, the SCs were collected and finally adjusted to $5 \times 10^{5}$ cells $/ \mu \mathrm{l}$. Then, $1 \mu \mathrm{l}$ of the cell suspension was mixed with $9 \mu$ l of RADA16-I peptide; the mixture was gently and quickly plated to dish in DMEM/F12 with $10 \%$ FBS. The medium was changed at 1,10 , and 30 min after plating, and once every 3 days during the following days. The images of living cells were taken by two-photon confocal microscope (Zeiss LSM510 META, Jena, Germany).

\section{Young Animals}

In vivo applications to brain wounds were carried out by using 16 postnatal day 5 (P5) Syrian hamster pups, anesthetized with whole-body cooling. The scalp was opened, and the optic tract within the superior colliculus was completely severed with a deep knife wound through a slot cut in the cartilaginous skull, extending
$1.5 \mathrm{~mm}$ below the surface, from the midline to a point beyond the lateral margin of the superior colliculus (9). Animals were kept alive 30 days after surgery. During surgery, eight animals were treated by injection into the brain wound of $10 \mu \mathrm{m}$ of $1 \%$ SAPNS. Control animals with the same lesions included eight injected with 10 $\mu \mathrm{m}$ isotonic saline (9).

\section{Surgical Procedures}

Thirty-two adult Sprague-Dawley rats (220-250 g) were used in this project. The rats were divided into six groups: (1) SAPNS only, (2) uncultured SAPNS with SCs group 1, 4, and 8 weeks, (3) precultured SAPNSSCs alone group 2 and 8 weeks. Group one had two wild-type rats; groups two and three had six for each time point. Rats were anesthetized with ketamine (80 $\mathrm{mg} / \mathrm{kg}$ ) and xylazine $(10 \mathrm{mg} / \mathrm{kg})$.

A dorsal laminectomy on the sixth and seventh cervical vertebrae was performed. The dura was incised longitudinally and pulled laterally. A spinal cord dorsal column transection was made between $\mathrm{C} 6$ and C7, followed by the removal of $1 \mathrm{~mm}$ of dorsal column tissue. Ten microliters of $1 \%$ SAPNS solution was injected into the lesion site or an equal volume of the cultured mixture of SAPNS and SCs, respectively, was transferred from the culture dish into the lesion cavity. After treatment the dura was closed. The muscle layers and skin were also closed with a suture. Manual bladder expression was performed twice daily until recovery of the bladder reflex.

All surgical procedures were approved by the Committee for the Use of Live Animals in Teaching and Research at the University of Hong Kong and MIT animal care committee.

\section{RESULTS}

\section{In Vitro}

Primary Neurons. In a 3D environment of SAPNS PC12 cells appeared to become senescent, and in serumfree (SF) condition, did not divide for 3 days in $0.5 \%$ SAPNS concentration, or 5 days in $1 \%$ SAPNS. When the cells reached the boundary of the SAPNS they proliferated at the normal rate until they reached confluence and then stopped dividing. This process was repeated three times. Using 2\% SAPNS concentration delayed proliferation of PC12 cells to day 7 in SF conditions. Care was taken during implantation of cells not to allow the culture medium to contact the cells during implantation in the culture. When NGF was added processes extended normally, but with a SAPNS concentrationdependant delay (Fig. 1). This was repeated in serum conditions; proliferation was only delayed 1 day past the 

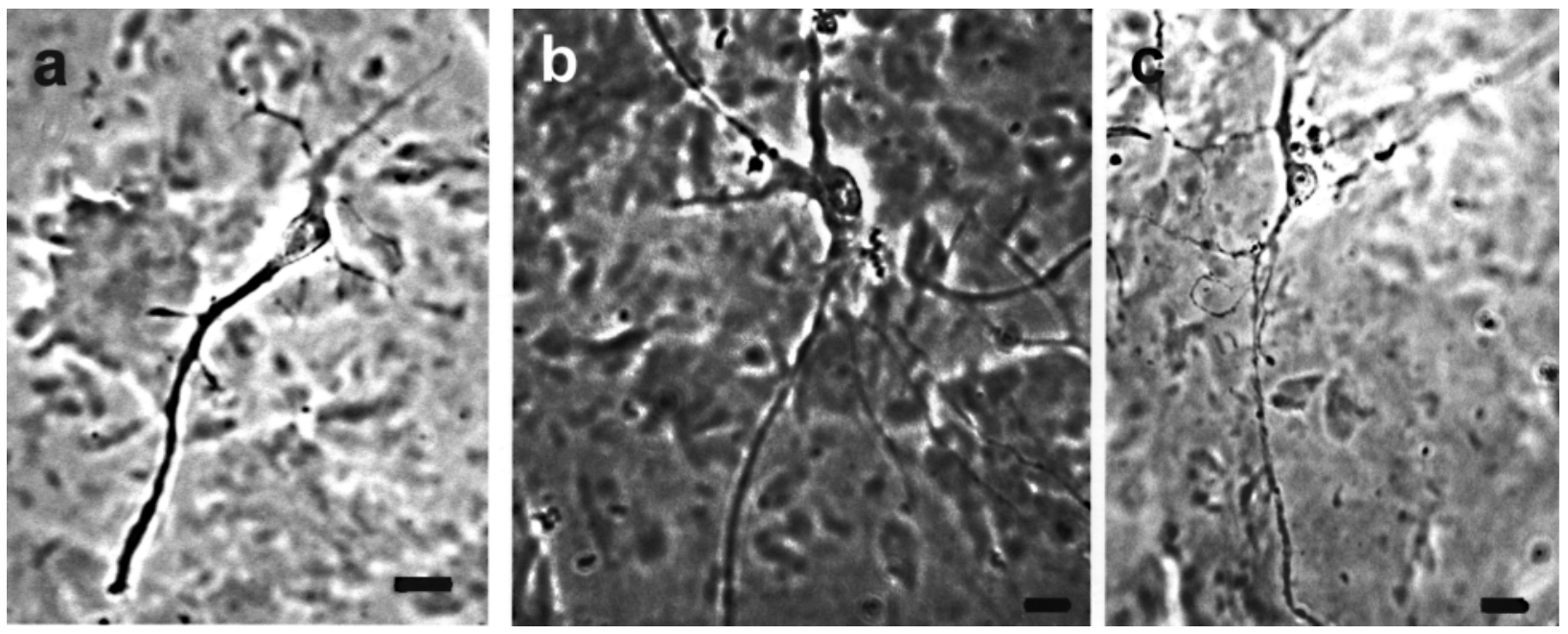

Figure 1. (a) PC12 cells grown in 2\% SAPNS and SF conditions, (b) $2 \%$ SAPNS and fetal bovine serum (FBS), (c) $1 \%$ SAPNS and FBS. Nerve growth factor (NGF) was added at day 10. All pictures were taken at day 17 after fixation. Note the increase in branching in the serum condition (b, c) and the increase in branch size in the higher modulus material (b). Scale bar: $20 \mu \mathrm{m}$.

control in the $0.5 \%$ condition, however in the higher concentrations of $1 \%$ and $2 \%$ division was observed at days 3 and 5, respectively.

For SCs, at a concentration of 5,000 cells $/ \mu 1,3$ days postimplantation in $1 \%$ SAPNS in vitro, no processes were observed. After 5 days processes were observed extending from the cell body. When SCs were implanted in $2 \%$ SAPNS, process extension was not observed until 5 days post-SAPNS implantation. Both conditions were in FBS. When the concentration of cells was increased

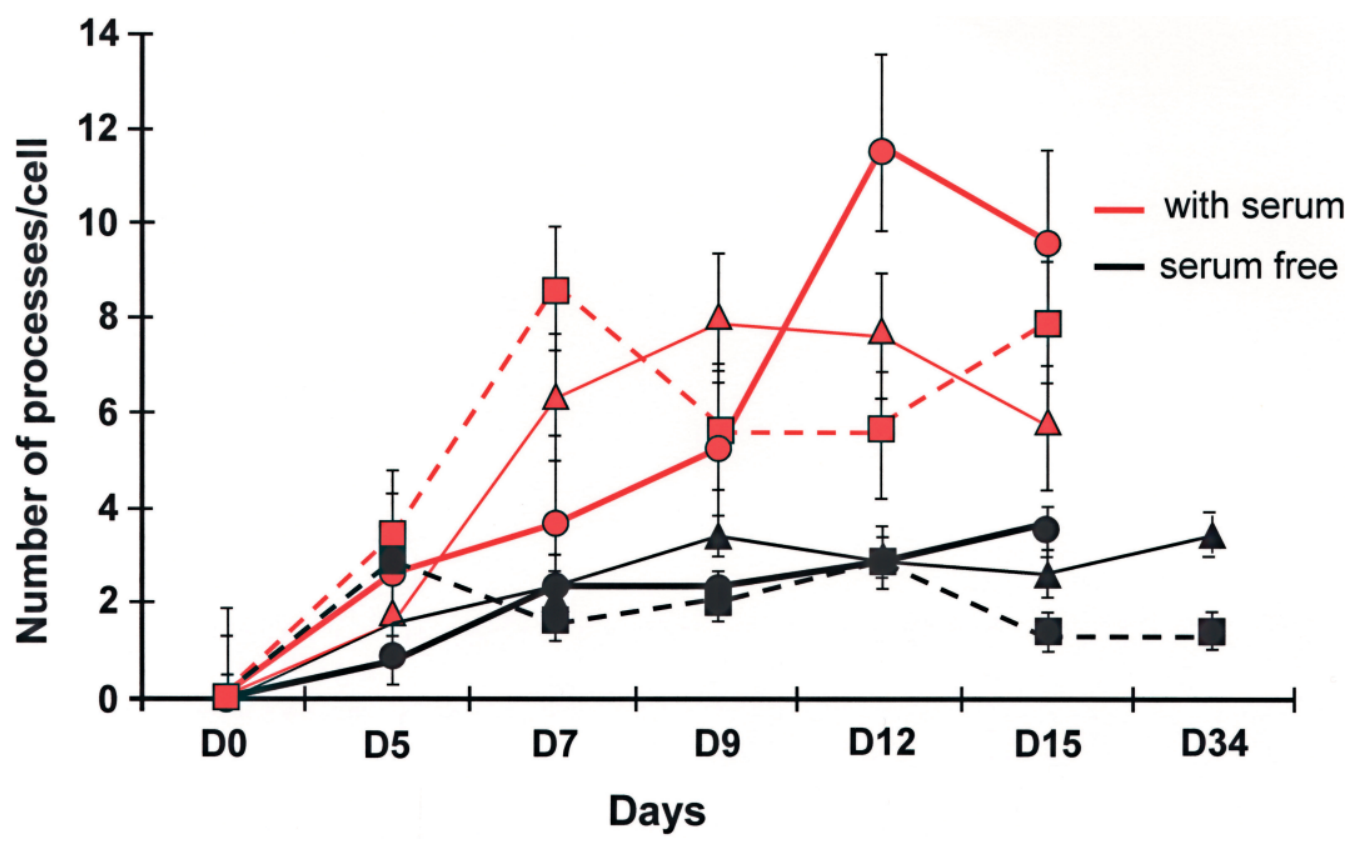

Figure 2. Number of processes per cell over time. All of the SF (black) conditions have less than four processes per cell, while the conditions with FBS (red) have greater than six processes by day 15. As the concentration of the material increases, the modulus of the material increases. Note: as the modulus increases so does the number of processes per cell over time. Circles, triangles, and squares represent $3 \%, 2 \%$, and $1 \%$, respectively. Error bars indicate SE. 


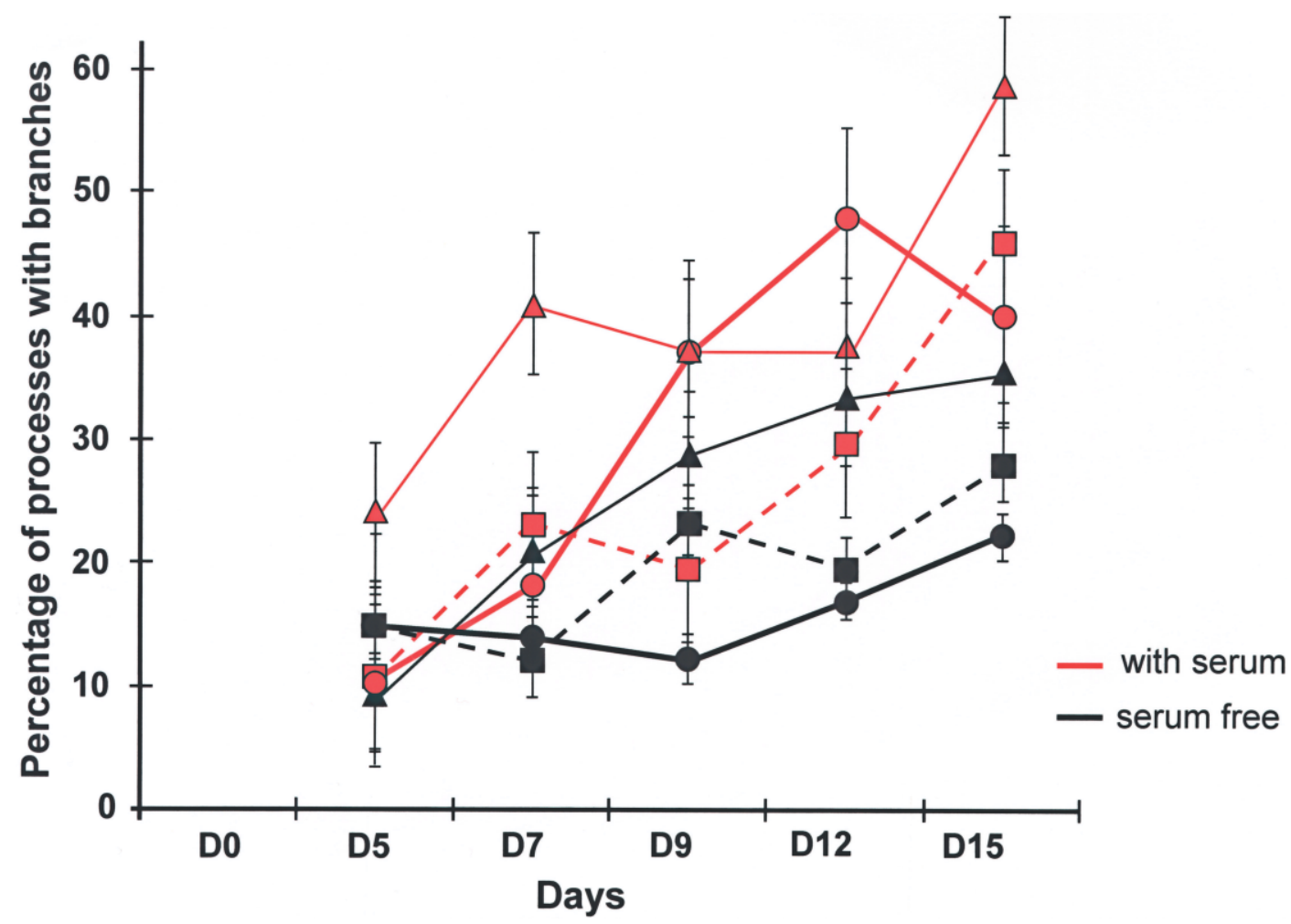

Figure 3. Branches per process. The graph shows the percentage of processes that have branches in each of the conditions. Circles, triangles, and squares represent $3 \%, 2 \%$, and $1 \%$, respectively. Error bars indicate SE.

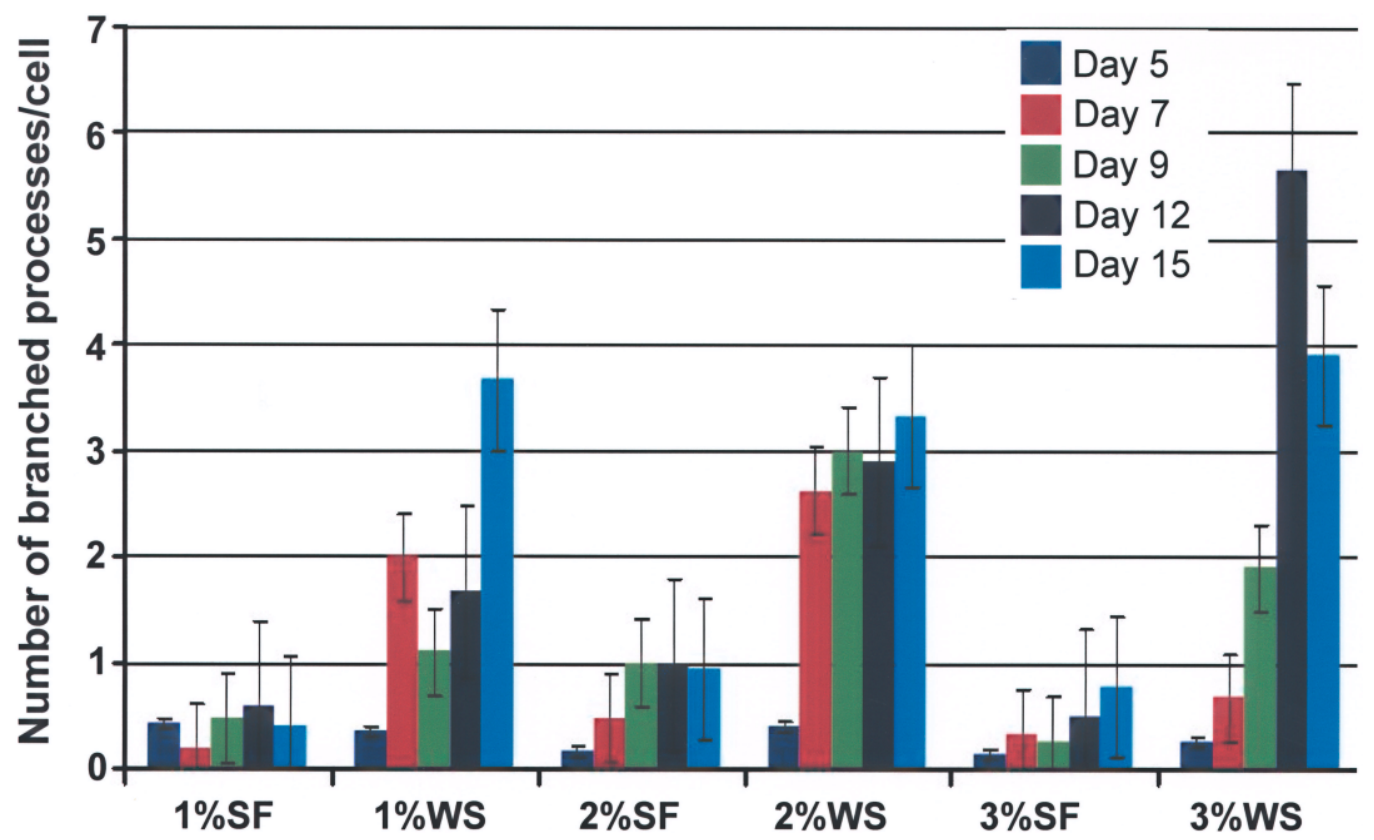

Figure 4. Branched processes per cell. Note that in the $1 \%$ and $3 \%$ SF conditions the number of branched processes is less than one. However, in $2 \%$ it reaches one. In all serum-added conditions the branched processes are over 1 after day 5 in the $1 \%$ and $2 \%$ serum-added conditions, and after day 7 in the $3 \%$ condition. Error bars indicate SE. 

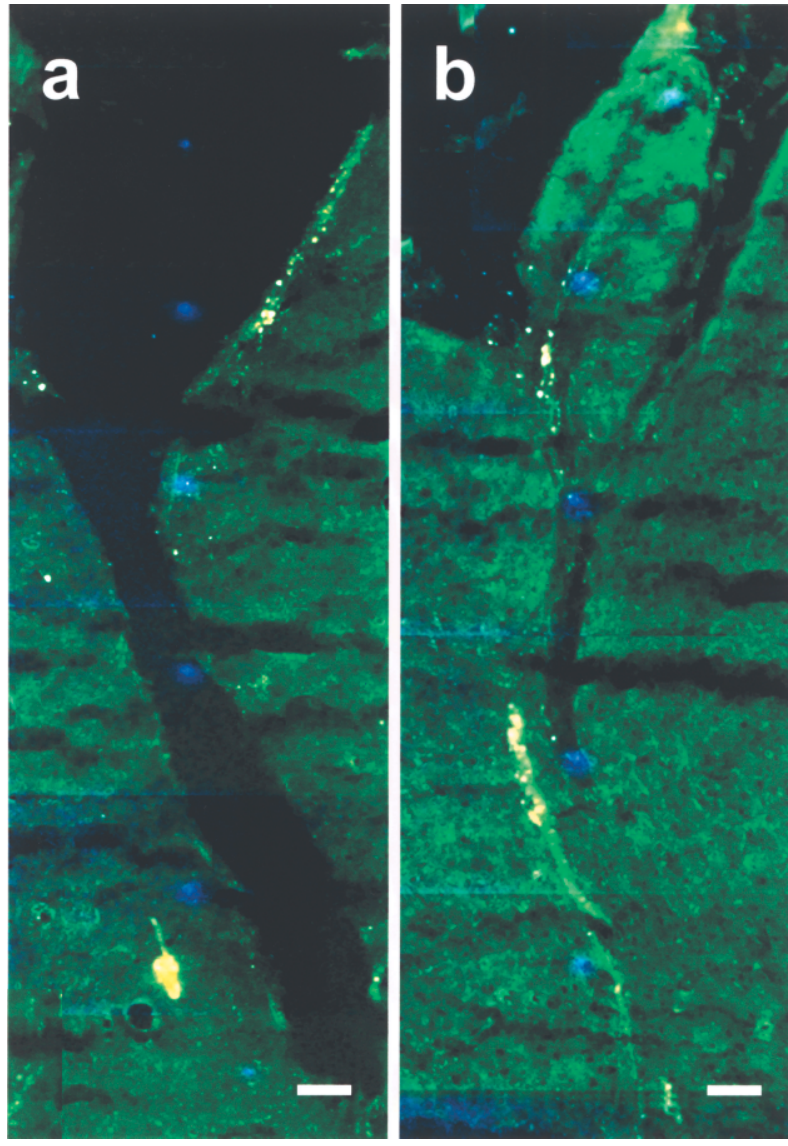

Figure 5. Parasagittal sections from animals 60 days postlesion and treatment. Arrows indicate the path and extent of knife cut. Animals sacrificed 30 days postlesion cases (a) is a saline control and (b) is an example of the peptide scaffoldtreated animals. Note the large gap in (a). In the peptide scaffold treatment case (b) the gap is completely gone and tissue has reconnected across the injury site. All peptide scaffold solution-treated cases appear to have reconnected at the site of the lesion. Scale bar: $100 \mu \mathrm{m}$.

to 10,000 cells $/ \mu 1$, process formation was delayed to 5 days in the $1 \%$ SAPNS concentration.

Neural Precursor Cells. Cells implanted in SAPNS at $1 \%$ concentration in $\mathrm{SF}$ conditions reached a maximum of $3 \pm 1$ processes per cell by day 5 of culture. With serum added they reached a maximum of $9 \pm 1$ processes per cell by day 7. Branching of the processes showed statistically significant differences. In SF conditions only $28 \%$ of the processes were branched by day 15 and the serum added had $45 \%$ of the total processes branched (Figs. 2 and 3).

For cells implanted in SAPNS at 2\% concentration, by day 9 of culture SF conditions reached a maximum of $3 \pm 1$ processes per cell. With serum added, by day 9 it reached a maximum of $8 \pm 1$ processes per cell. Branching of the processes showed statistically signifi- cant differences. In SF conditions only 35\% of the processes were branched by day 15 and the serum added had $58 \%$ of the total processes branched. If cells were plated in 2\% it took longer, up to 5-7 days before observing processes emerge. The processes continued to grow up to 30 days.

In cells implanted in SAPNS at 3\% concentration SF conditions reached a maximum of $3.5 \pm 1$ processes per cell by day 15 of culture. With serum added cells reached a maximum of $11.5 \pm 1$ processes per cell by day 12. Branching of the processes showed statistically significant differences. In SF conditions only $22 \%$ of the processes were branched by day 15 ; the serum added had $48 \%$ of the total processes branched by day 12 .

In all SF conditions the number of branched processes per cell remained below 1 . The serum-added conditions after day 5 had more than one branched process per cell. As the concentration of the SAPNS increased there was an increase in the number of branches in the serum conditions. The maximum number of branched processes per cell reached was $5.5 \pm 1$, in the serum-added condition 3\% SAPNS condition at day 12 (Fig. 4).

\section{In Vivo}

Brain. In P5 hamsters cells migrated into the $1 \%$ SAPNS implantation after transection in the superior colliculus in seven out of eight cases. All controls had cavities at 1 month survival in the location of the lesion (Fig. 5).

Spinal Cord. One percent SAPNS implanted into the spinal cord alone eliminated the cysts when there was enough CSF and other ionic material left in the surgical site to buffer the material when implanted at the lesion site. This was repeated twice (Fig. 6).

Schwann Cell Implantation Into the Spinal Cord. Cells mixed with unbuffered 1\% SAPNS and directly implanted showed apoptosis and necrosis (17) as well as a reduced cyst formation at 4 and 8 weeks, compared with untreated controls (Fig. 7).

Prebuffered $1 \%$ SAPNS with cells showed no cyst or cavity formation at 2 weeks or 8 weeks. Also, cells migrated into and out of the implantation site and were evident at up to a centimeter from the lesion site (Fig. 8).

\section{DISCUSSION}

The ability to keep the cells forever young during implantation is very important to the reconstitution of tissue or organs being replaced. In the emerging field of stem cells there is a need for an environment that can be tuned to the needs of the cells to slow down the differentiation or proliferation in vitro or in vivo while remaining invisible to the immune system. We have shown that when cells are placed into a defined system we can 


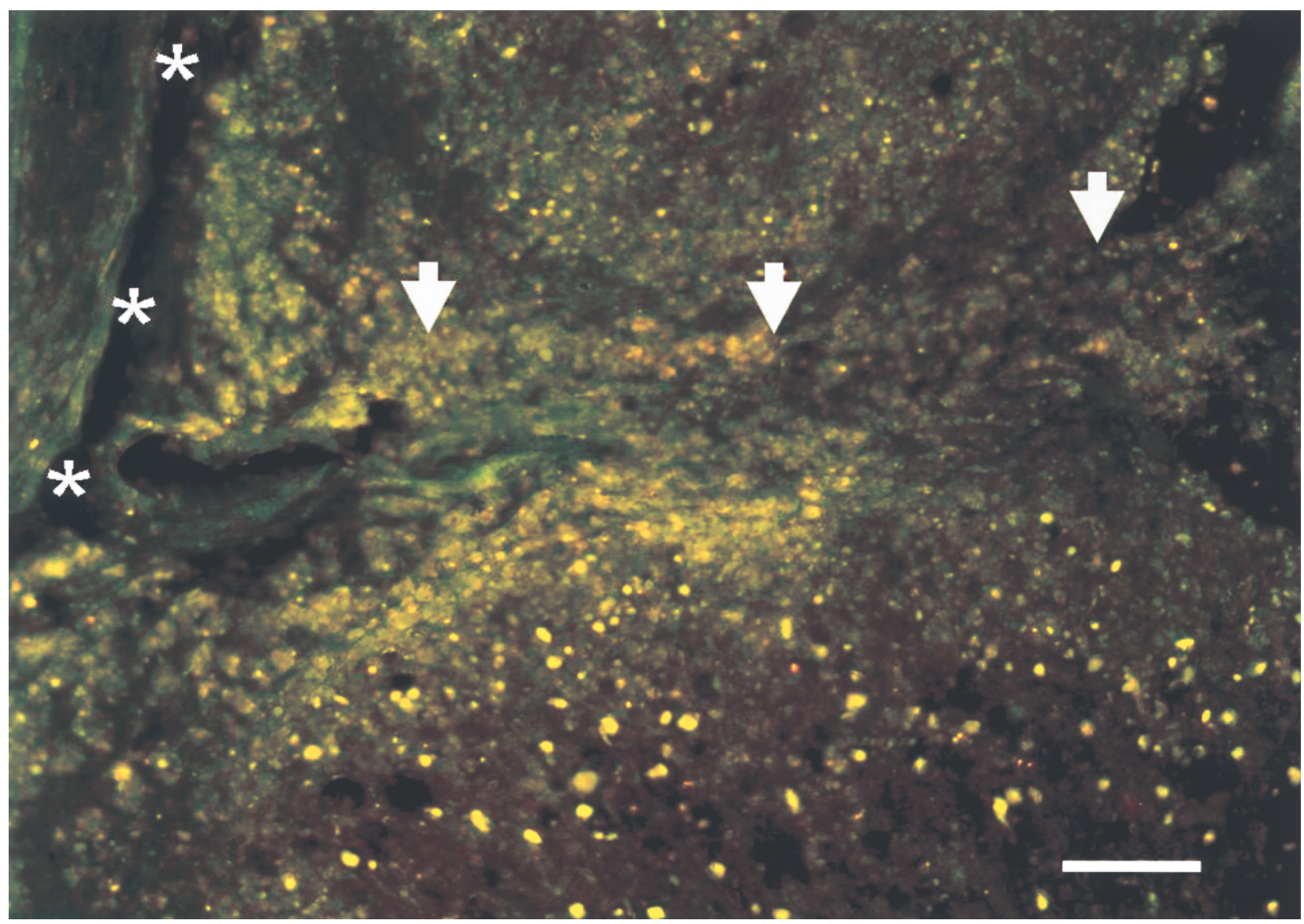

Figure 6. Spinal cord with $1 \%$ SAPNS implanted after the removal of $1.5 \mathrm{~mm}$ of spinal cord. Note the lack of cyst and the surrounding cells have migrated into the site (arrows). Scale bar: $200 \mu \mathrm{m}$.

delay their proliferation, differentiation, and maturation depending on the density of the cell population, density of the matrix, and the local environment. This is done in a 3D environment that allows the benefits of cell therapy to be more fully realized.

\section{Extracellular Matrix Mimic}

This set of experiments points to new ways of thinking about cell therapy and how the modulus and the breakdown of an implanted matrix affect the lesion and perilesion environment. Due to the porosity of this material at the nanoscale, the ability for $\mathrm{T}$ cells to migrate into the treated environment seems to be greatly reduced $(8,9,17)$. The body does not look at this material as a foreign material; it actually treats the material as it would treat the extracellular matrix. This extracellular matrix mimic does some very interesting things, not only to the implanted cells, but also to the surrounding tissue, such as changing the interface between the tissue and the implant where a scar would normally form.

\section{Surface Interaction}

Using the analogy of inserting one's hand into a bowl of rice, the rice looks solid but the little grains of rice move out of the way of the hand and then come back around the wrist. SAPNS appears to work in a very similar fashion; it does not covalently bond but is held together by weak ionic and van der Waal's interactions. These interactions allow the material to self-assemble along the hydrophobic backbone, and hydrophilic fingers that stick out perpendicular to the direction of the fiber. The edges of the fiber are exposed and when a cell interacts with the fiber, it causes a destabilization of the nanodomain at the contact point with the fiber. The fiber disassembles to allow the cell to migrate into it, and then reassembles on the other side of the cell. An analogy would be: the cell's charge opens the door, the cell walks through the door, and the door shuts behind it. Then the next door opens, and so forth.

Because this is a dynamic process, and not a perma- 
nent process, the assembly and disassembly of this material is very important for the controlled access to the environment. It is creating an area that is less dense, one that enables cells to migrate into this area. In early development the density of the ECM is much lower than in the adult stage. This differential density allows for migration in a directed fashion. The matrix dynamic can be modulated by the density and the motility of the local environment.

\section{Concentration-Dependent Response}

There also appears to be a concentration/modulusdependant growth rate of the neural precursor cells when placed in culture. In the presence of serum we observe that the higher the modulus, the more overall processes per cell. In serum-free conditions we do not see the modulus-dependant component in NPCs. The SAPNS appears to slow the growth rate and differentiation of the cells, thus allowing them to acclimate to the environment. This will be very important when the immune system tries attacking the cells when placed in vivo.

The NPCs appear to grow, or not grow, depending on the addition of the serum. With serum, the NPCs exhibit a concentration-dependant change in the response rate: the higher the concentration of SAPNS, the tighter the matrix. The ability of the serum to diffuse into the SAPNS shows a concentration-dependant response. In the $3 \%$ SAPNS concentration the number and the branch formation of the processes from the cells is delayed until day 9 ; in the $2 \%$ concentration the re- sponse is seen on day 7. In the lowest concentration the response is seen at day 5. All of this, of course, is dependent upon the volume of the SAPNS and the surface area of the bolus. When implanted in vivo this is much more pronounced, due to the limited ability of any material to diffuse across the implant boundary The higher the concentration of the SAPNS in vivo, the slower it will breakdown.

The control of proliferation in PC12 cells is cell-cell contact. When the cells grow to confluence they stop dividing. This appears to be the case when the cells are implanted into the SAPNS at different concentrations. This cell-cell mimic (SAPNS) controls the cell proliferation rate. The PC12 cells were able to grow normally after implantation in SAPNS. When NGF is added, normal transformation of the cells and neurite extension is observed. There are differences that need to be pointed out: (a) the higher the concentration of the SAPNS the slower the neurite extension (b) with the increased modulus of the material, due to concentration, our results agree with Leach (32): the increase in density tends to have an increase in branches; and (c) after adding NGF the morphology of growth changes, depending on the modulus of the environment.

\section{Schwann Cells and NPCs}

There appears to be a similar reaction to the concentration of the material and the cell density that decreases proliferation and differentiation. The fundamental change in growth pattern gives us new directions for the manip-
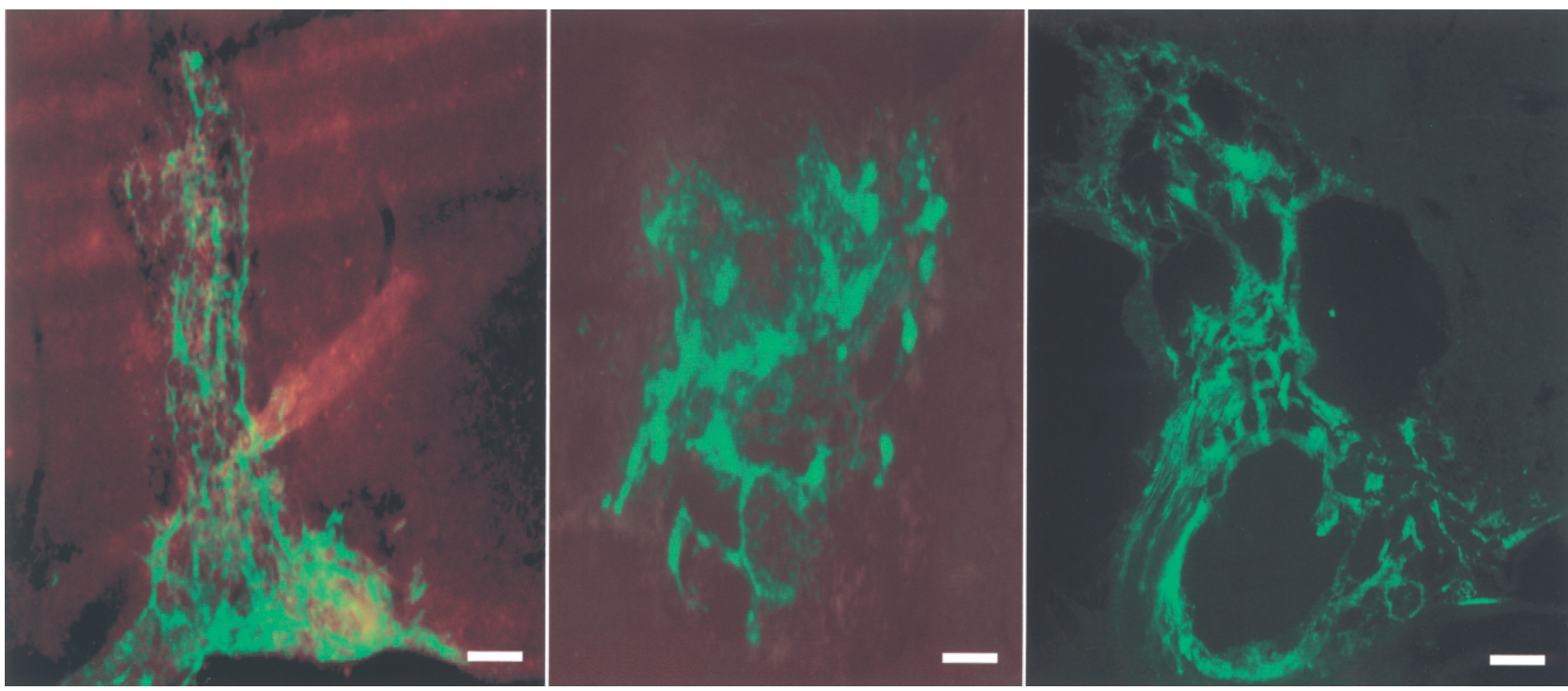

Figure 7. Schwann cells implanted into the spinal cord at 1, 4, and 8 weeks after implantation into the spinal cord. Disassociated cells were mixed with $1 \%$ SAPNS and implanted immediately after removing part of the spinal cord. Note: at 4 and 8 weeks there are several cysts where the low $\mathrm{pH}$ of the material may have caused the cyst formation and an acid shock. This is very similar to that in other scaffolds during breakdown. The reduction in $\mathrm{pH}$ will cause cellular apoptosis. Scale bar: $500 \mu \mathrm{m}$. 

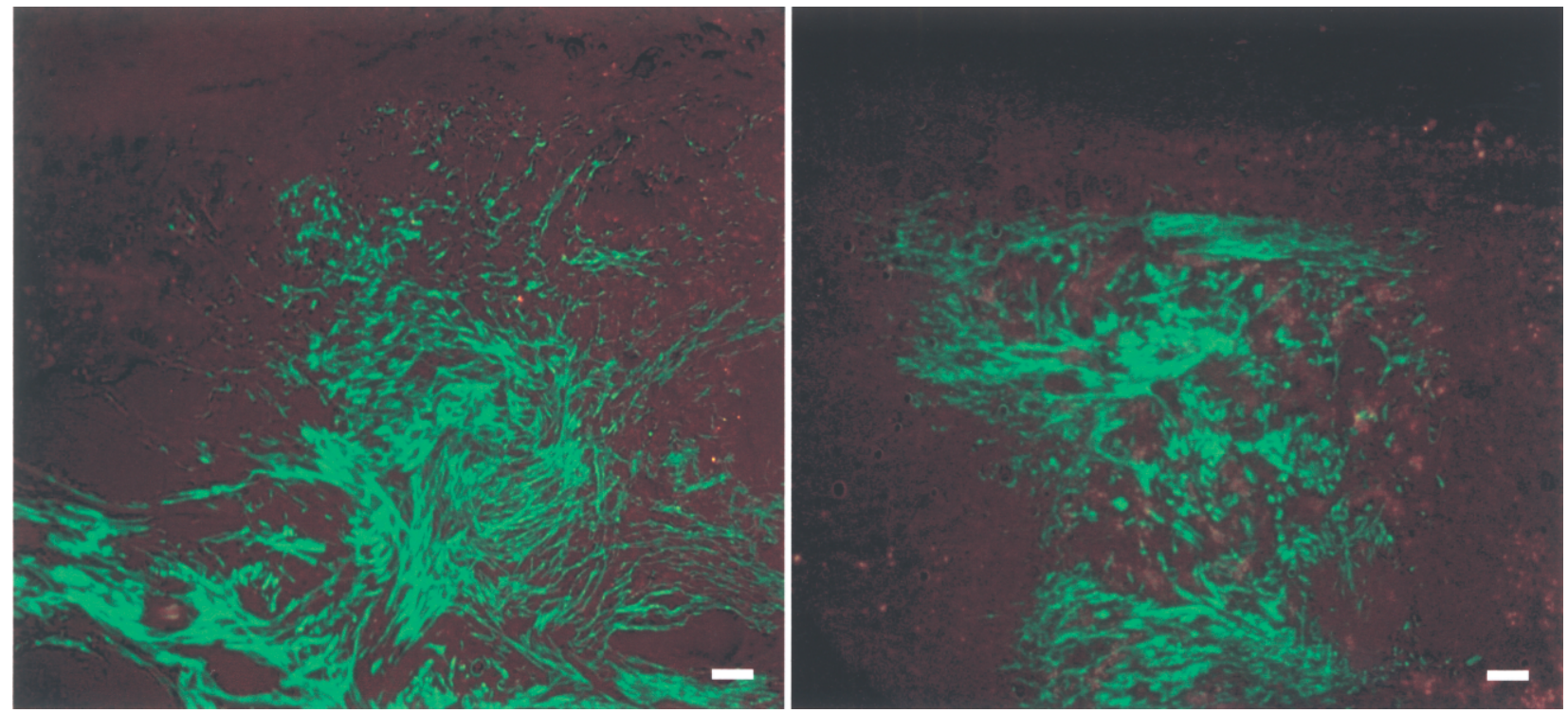

Figure 8. Prebuffered 1\% SAPNS with Schwann cells implanted into the spinal cord. Left is 2 weeks and right is 8 weeks survival. There is good integration and distinct lack of boundary. Scale bar: $200 \mu \mathrm{m}$.

ulation of the cell's growth program and the local immune system. Because the body does not treat the SAPNS as a foreign material, it can be used in a fashion similar to an early development ECM that allows for the migration of support cells into a treated area, thus allowing for the reprogramming, delay of the growth program, or protection of the implanted cells. Also, by manipulating the concentration of the implanted cells, the environment of early development can be mimicked, and until the cells are signaled they will remain in stasis for an extended period.

\section{pH Contribution}

There is also a $\mathrm{pH}$ contribution to the delay of the differentiation and growth of the cells. If the material is not buffered properly then there will be an acid shock; the cells that are in the implant of SAPNS will slowly disappear. This is shown in the spinal cord implant when the GFP SCs are mixed and implanted before they are buffered; the appearances of cysts are an indication of an acid shock.

In the first implant of SAPNS at $1 \%$ concentration into a spinal cord without prebuffering, healing of the cord was evident. The injection of the preassembled material was made into a cavity that had a mixture of blood and CSF that allowed for immediate buffering of the SAPNS. During subsequent implantations of added cells and SAPNS, the lesion site was free of blood and CSF and therefore did not allow for sufficient buffering of the local environment. Buffered implantations are shown in Figures 5, 6, and 8; unbuffered implantations are shown in Figure 7. When the SAPNS was injected into the lesion site of the hamster the existing CSF was sufficient for immediate buffering of the material. We did not see the acid response, where the cells die over time during breakdown, because the SAPNS does not break down acidically.

\section{Serum Free}

The fact that cells can survive in SF condition is very beneficial because it provides much greater control over the medium chosen to grow the cells in vitro, before implanting them into a tissue. In culture, using disassociated hippocampal cells from embryonic animals, we observe that the branching rates are lower in the SF conditions, signaling that the growth and differentiation of the cells is more controlled temporally. In every cell type we have worked with SF branching is a fraction of what we found for the serum-added condition.

\section{CONCLUSION}

By manipulating the cell density and SAPNS concentration we can control the nanoenvironment surrounding PC12 cells, Schwann cells, and NPCs, and thereby we can control the proliferation, elongation, differentiation, and maturation in vitro. We also extended the control of the nano environment using SAPNS to implants in the brain and spinal cord without cells. Finally, we showed that a combination of SAPNS and young cells can be transplanted into a mammal, eliminating the need for immunosuppressants. 
ACKNOWLEDGMENTS: This work was supported with an award from the Deshpande Center for Technological Innovation at MIT and with a University of Hong Kong Technology Transfer Seed Fund grant.

\section{REFERENCES}

1. Archibald, S. J.; Krarup, C.; Shefner, J.; Li, S. T.; Madison, R. D. A collagen-based nerve guide conduit for peripheral nerve repair: An electrophysiological study of nerve regeneration in rodents and nonhuman primates. J. Comp. Neurol. 306:685-696; 1991.

2. Aubert-Pouessel, A.; Venier-Julienne, M. C.; Clavreul, A.; Sergent, M.; Jollivet, C.; Montero-Menei, C. N.; Garcion, E.; Bibby, D. C.; Menei, P.; Benoit, J. P. In vitro study of GDNF release from biodegradable PLGA microspheres. J. Control. Release 95:463-475; 2004.

3. Belkas, J. S.; Munro, C. A.; Shoichet, M. S.; Johnston, M.; Midha, R. Long-term in vivo biomechanical properties and biocompatibility of poly(2-hydroxyethylmethacrylate-co-methyl methacrylate) nerve conduits. Biomaterials 26:1741-1749; 2005.

4. Burdick, J. A.; Ward, M.; Liang, E.; Young, M. J.; Langer, R. Stimulation of neurite outgrowth by neurotrophins delivered from degradable hydrogels. Biomaterials 27:452-459; 2006.

5. Carone, T. W.; Hasenwinkel, J. M. Mechanical and morphological characterization of homogeneous and bilayered poly(2-hydroxyethyl methacrylate) scaffolds for use in CNS nerve regeneration. J. Biomed. Mater. Res. B Appl. Biomater. 78:274-282; 2006.

6. Crompton, K. E.; Goud, J. D.; Bellamkonda, R. V.; Gengenbach, T. R.; Finkelstein, D. I.; Horne, M. K.; Forsythe, J. S. Polylysine-functionalised thermoresponsive chitosan hydrogel for neural tissue engineering. Biomaterials 28:441-449; 2007.

7. Ellis-Behnke, R. G. Nano neurology and the 4 Ps of CNS regeneration: Preserve, permit, promote and plasticity. Med. Clin. North Am. 91(5):937-962; 2007.

8. Ellis-Behnke, R. G.; Liang, Y. X.; Tay, D. K. C.; Kau, W. F.; Schneider, G. E.; Zhang, S.; Wu, W.; So, K. F. Nano hemostat solution: Immediate hemostasis at the nanoscale. Nanomedicine 2:207-215; 2006.

9. Ellis-Behnke, R. G.; Liang, Y. X.; You, S. W.; Tay, D. K. C.; Zhang, S.; So, K. F.; Schneider, G. E. Nano neuro knitting: Peptide nanofiber scaffold for brain repair and axon regeneration with functional return of vision. Proc. Nat. Acad. Sci. USA 103:5054-5059; 2006.

10. Ellis-Behnke, R. G.; Teather, L. A.; Schneider, G. E.; So, K. F. Using nanotechnology to design potential therapies for CNS regeneration. Curr. Pharm. Des. 13:2519-2528; 2007.

11. Enomoto, M.; Shinomiya, K.; Okabe, S. Migration and differentiation of neural progenitor cells from two different regions of embryonic central nervous system after transplantation into the intact spinal cord. Eur. J. Neurosci. 17:1223-1232; 2003.

12. Fawcett, J. A.; Asher, R. A. The glial scar and central nervous system repair. Brain Res. Bull. 49:377-391; 1999.

13. Freier, T.; Koh, H. S.; Kazazian, K.; Shoichet, M. S. Controlling cell adhesion and degradation of chitosan films by $\mathrm{N}$-acetylation. Biomaterials 26:5872-5878; 2005.

14. Freier, T.; Montenegro, R.; Shan Koh, H.; Shoichet, M. S.
Chitin-based tubes for tissue engineering in the nervous system. Biomaterials 26:4624-4632; 2005.

15. Guan, J.; Stankus, J. J.; Wagner, W. R. Development of composite porous scaffolds based on collagen and biodegradable poly(ester urethane)urea. Cell Transplant. 15(Suppl. 1):S17-27; 2006.

16. Gundabolu, P.; Shurey, S.; Maquet, V.; Sibbons, P. D.; Boccaccini, A. R.; Gabe, S. M. A pilot study investigating a novel subcutaneously implanted pre-cellularised scaffold for tissue engineering of intestinal mucosa. Eur. Cell. Mater. 11:27-33; 2006.

17. Guo, J.; Su, H.; Zeng, Y.; Liang, Y. X.; Ellis-Behnke, R. G.; So, K. F.; Wu, W. Reknitting the injured spinal cord using a self-assembling peptide nanofiber scaffold. Nanomedicine 3:311-321; 2007.

18. Gupta, D.; Tator, C. H.; Shoichet, M. S. Fast-gelling injectable blend of hyaluronan and methylcellulose for intrathecal, localized delivery to the injured spinal cord. Biomaterials 27:2370-2379; 2006.

19. Hahn, S. K.; Jelacic, S.; Maier, R. V.; Stayton, P. S.; Hoffman, A. S. Anti-inflammatory drug delivery from hyaluronic acid hydrogels. J. Biomater. Sci. Polym. Ed. 15:11111119; 2004.

20. HemCon Medical Technologies, Inc. FAQs: Shellfish allergy study. www.interventionalhp.com/faq.php.

21. Herbert, C. B.; Bittner, G. D.; Hubbell, J. A. Effects of fibinolysis on neurite growth from dorsal root ganglia cultured in two- and three-dimensional fibrin gels. J. Comp. Neurol. 365:380-391; 1996.

22. Holmes, T. Novel peptide-based biomaterial scaffolds for tissue engineering. Trends Biotechnol. 20:16-21; 2002.

23. Holmes, T. C.; de Lacalle, S.; Su, X.; Liu, G.; Rich, A.; Zhang, S. Extensive neurite outgrowth and active synapse formation on self-assembling peptide scaffolds. Proc. Natl. Acad. Sci. USA 97:6728-6733; 2000.

24. Hou, S.; Tian, W.; Xu, Q.; Cui, F.; Zhang, J.; Lu, Q.; Zhao, C. The enhancement of cell adherence and inducement of neurite outgrowth of dorsal root ganglia cocultured with hyaluronic acid hydrogels modified with Nogo-66 receptor antagonist in vitro. J. Neurosci. 137: 519-529; 2006.

25. Johe, K. K.; Hazel, T. G.; Muller, T.; Dugich-Djordjevic, M. M.; Mckay, R. D. Single factors direct the differentiation of stem cells from the fetal and adult central nervous system. Genes Dev. 10:3129-3140; 1996.

26. Kataoka, K.; Suzuki, Y.; Kitada, M.; Hashimoto, T.; Chou, H.; Bai, H.; Ohta, M.; Wu, S.; Suzuki, K.; Ide, C. Alginate enhances elongation of early regenerating axons in spinal cord of young rats. Tissue Eng. 10:493-504; 2004.

27. Kataoka, K.; Suzuki, Y.; Kitada, M.; Ohnishi, K.; Suzuki, K.; Tanihara, M.; Ide, C.; Endo, K.; Nishimura, Y. Alginate, a bioresorbable material derived from brown seaweed, enhances elongation of amputated axons of spinal cord in infant rats. J. Biomed. Mater. Res. 54:373-384; 2001.

28. Kim, D. H.; Martin, D. C. Sustained release of dexamethasone from hydrophilic matrices using PLGA nanoparticles for neural drug delivery. Biomaterials 27:3031-3037; 2006.

29. Krause, T. L.; Bittner, G. D. Rapid morphological fusion of severed myelinated axons by polyethylene glycol. Proc. Natl. Acad. Sci. USA 87:1471-1475; 1990.

30. Lam, X. M.; Duenas, E. T.; Cleland, J. L. Encapsulation and stabilization of nerve growth factor into poly(lactic- 
co-glycolic) acid microspheres. J. Pharm. Sci. 90:13561365; 2001.

31. Langer, R. Drug delivery and targeting. Nature 392(Suppl.): 5-10; 1998.

32. Leach, J.; Brown, X.; Jacot, J.; DiMilla, P.; Wong, J. Neurite outgrowth and branching of PC 12 cells on very soft substrates sharply decreases below a threshold of substrate rigidity. J. Neural Eng. 4:26-34; 2007.

33. Mahoney, M. J.; Anseth, K. S. Three-dimensional growth and function of neural tissue in degradable polyethylene glycol hydrogels. Biomaterials 27:2265-2274; 2006.

34. Mahoney, M. J.; Krewson, C.; Miller, J.; Saltzman, W. M. Impact of cell type and density on nerve growth factor distribution and bioactivity in 3-dimensional collagen gel cultures. Tissue Eng. 12:1915-1927; 2006.

35. Morrissey, T. K.; Kleitman, N.; Bunge, R. P. Isolation and functional characterization of Schwann cells derived from adult peripheral nerve. J. Neurosci. 11:2433-2442; 1991.

36. Newman, K.; McBurney, M. Poly (D,L lactic-co-glycolic acid) microspheres as biodegradable microcarriers for pluripotent stem cells. Biomaterials 25:5763-5771; 2004.

37. Nomura, H.; Katayama, Y.; Shoichet, M. S.; Tator, C. H. Complete spinal cord transection treated by implantation of a reinforced synthetic hydrogel channel results in syringomyelia and caudal migration of the rostral stump. Neurosurgery $59: 183-192 ; 2006$.

38. Patist, C. M.; Mulder, M. B.; Gautier, S. E.; Maquet, V.; Jerome, R.; Oudega, M. Freeze-dried poly(D,L-lactic acid) macroporous guidance scaffolds impregnated with brain-derived neurotrophic factor in the transected adult rat thoracic spinal cord. Biomaterials 25:1569-1582; 2004.

39. Pelham, Jr., R. J.; Wang, Y. Cell locomotion and focal adhesions are regulated by substrate flexibility. Proc. Natl. Acad. Sci. USA 94:13661-13665; 1997.

40. Piantino, J.; Burdick, J. A.; Goldberg, D.; Langer, R.; Benowitz, L. I. An injectable, biodegradable hydrogel for trophic factor delivery enhances axonal rewiring and improves performance after spinal cord injury. Exp. Neurol. 201:359-367; 2006.

41. Prang, P.; Muller, R.; Eljaouhari, A.; Heckmann, K.; Kunz, W.; Weber, T.; Faber, C.; Vroemen, M.; Bogdahn, U.; Weidner, N. The promotion of oriented axonal regrowth in the injured spinal cord by alginate-based anisotropic capillary hydrogels. Biomaterials 27:3560-3569; 2006.

42. Sakiyama, S. E.; Schense, J. C.; Hubbell, J. A. Incorporation of heparin-binding peptides into fibrin gels enhances neurite extension: An example of designer matrices in tissue engineering. FASEB J. 13:2214-2224; 1999.

43. Sakiyama-Elbert, S. E.; Hubbell, J. A. Development of fibrin derivatives for controlled release of heparin-binding growth factors. J. Control. Release 65:389-402; 2000.

44. Sakiyama-Elbert, S. E.; Hubbell, J. A. Controlled release of nerve growth factor from a heparin-containing fibrinbased cell ingrowth matrix. J. Control. Release 69:149$158 ; 2000$.

45. Schmidt, C.; Leach, J. Neural tissue engineering: Strategies for repair and regeneration. Ann. Rev. Eng. 5:295347; 2003.

46. Segura, T.; Anderson, B. C.; Chung, P. H.; Webber, R. E.; Shull, K. R.; Shea, L. D. Crosslinked hyaluronic acid hydrogels: A strategy to functionalize and pattern. Biomaterials 26:359-371; 2005.
47. Takenaga, M.; Ohta, Y.; Tokura, Y.; Hamaguchi, A.; Suzuki, N.; Nakamura, M.; Okano, H.; Igarashi, R. Plasma as a scaffold for regeneration of neural precursor cells after transplantation into rats with spinal cord injury. Cell Transplant. 16:57-65; 2007.

48. Taylor, S. J.; McDonald, 3rd, J. W.; Sakiyama-Elbert, S. E. Controlled release of neurotrophin-3 from fibrin gels for spinal cord injury. J. Control. Release 98:281-294; 2004.

49. Taylor, S. J.; Rosenzweig, E. S.; McDonald, 3rd, J. W.; Sakiyama-Elbert, S. E. Delivery of neurotrophin-3 from fibrin enhances neuronal fiber sprouting after spinal cord injury. J. Control. Release 113:226-235; 2006.

50. Taylor, S. J.; Sakiyama-Elbert, S. E. Effect of controlled delivery of neurotrophin-3 from fibrin on spinal cord injury in a long term model. J. Control. Release 116:204210; 2006.

51. Teng, Y. D.; Lavik, E. B.; Qu, X.; Park, K. I.; Ourednik, J.; Zurakowski, D.; Langer, R.; Snyder, E. Y. Functional recovery following traumatic spinal cord injury mediated by a unique polymer scaffold seeded with neural stem cells. Proc. Natl. Acad. Sci. USA 99:3024-3029; 2002.

52. Tian, W. M.; Hou, S. P.; Ma, J.; Zhang, C. L.; Xu, Q. Y.; Lee, I. S.; Li, H. D.; Spector, M.; Cui, F. Z. Hyaluronic acidpoly-D-lysine-based three-dimensional hydrogel for traumatic brain injury. Tissue Eng. 11:513-525; 2005.

53. Tsai, E. C.; Dalton, P. D.; Shoichet, M. S.; Tator, C. H. Synthetic hydrogel guidance channels facilitate regeneration of adult rat brainstem motor axons after complete spinal cord transection. J. Neurotrauma 21:789-804; 2004.

54. Tsai, E. C.; Dalton, P. D.; Shoichet, M. S.; Tator, C. H. Matrix inclusion within synthetic hydrogel guidance channels improves specific supraspinal and local axonal regeneration after complete spinal cord transection. Biomaterials 27:519-533; 2006.

55. Willerth, S. M.; Sakiyama-Elbert, S. E. Approaches to neural tissue engineering using scaffolds for drug delivery. Adv. Drug Deliv. Rev. 59:325-338; 2007.

56. Willerth, S. M.; Sakiyama-Elbert, S. E. Cell therapy for spinal cord regeneration. Adv. Drug Deliv. Rev. 60:263276; 2008.

57. Xu, X. M.; Guénard, V.; Kleitman, N.; Bunge, M. Axonal regeneration into SC-seeded guidance channels grafted into transected adult rat spinal cord. J. Comp. Neurol. 351: 145-160; 1995.

58. Zhang, S. Fabrication of novel biomaterials through molecular self-assembly. Nat. Biotechnol. 21:1171-1178; 2003.

59. Zhang, S.; Holmes, T. C.; DiPersio, C. M.; Hynes, R. O.; $\mathrm{Su}, \mathrm{X}$.; Rich, A. Self-complementary oligopeptide matrices support mammalian cell attachment. Biomaterials 16: 1385-1393; 1995.

60. Zhang, S.; Holmes, T.; Lockshin, C.; Rich, A. Spontaneous assembly of a self-complementary oligopeptide to form a stable macroscopic membrane. Proc. Natl. Acad. Sci. USA 90:3334-3338; 1993.

61. Zhang, S.; Marini, D. M.; Hwang, W.; Santoso, S. Design of nanostructured biological materials through self-assembly of peptides and proteins. Curr. Opin. Chem. Biol. 6: 865-871; 2002. 